\title{
Study on Effective Way to Reduce Construction Waste using R Programming
}

\author{
M. Seema Thenmozhi ${ }^{1}$, K. Divakar ${ }^{2}$ \\ ${ }^{1}$ PG Scholar, Coimbatore Institute of Technology, Coimbatore \\ ${ }^{2}$ Professor, Coimbatore Institute of Technology, Coimbatore
}

\begin{abstract}
The construction sector may be a second largest industry in India after agriculture. It makes a considerable impact on the economy and provides employment to an outsized number of individuals .This project consists of an investigation on the incidence of residential construction waste in Coimbatore. Waste within the construction sector has been the topic of various research projects round the globe in recent years. There are different approaches adopted to reduce the amount of waste generated in the construction industry. The present research is aimed at to identify the processes that produce waste, Classification of waste in a technologically advanced manner and to identify alternatives that can be adopted to reduce waste. The main focus of the study is to design systematic approach to be adopted for waste quantification and reduction. The current study focuses on residential construction projects. The top three activities that cause the most amount of waste are identified. For this, we have adopted questionnaire technique and supported that the activities are ranked and causes are identified. Recommendations are given to the firm supported analysis to reinforce the method and minimize the waste.
\end{abstract}

Keywords: Construction Waste, Waste Management, Civil works, Severity Index.

\section{INTRODUCTION}

Construction waste has proven to have a negative impact on the budget of construction and environmental businesses too. Weighing current methods of waste assessment, questionnaires will transpire to recognize the most frequent categories that produce the construction waste on site affecting the final cost of the residential projects, the types of waste and their potential causes. The questionnaires will be sent to construction companies. First, construction works that produce the highest amount of waste will be selected. Second, predominant causes and types of waste will be identified by the second questionnaire for top three activities. Third, implementation and recommendation will be chosen according to the previous study and it is given to the same construction companies which will help them to minimize the waste in terms of cost, material and quality.

The construction industry represents one of the most important sectors of the economy of the United States with ten percent of the gross national product (Clough et al., 2000). The residential segment represents 40 to $45 \%$ of all new construction in the country. However this sector is commonly characterized as a "backward industry" if compared with other sectors of the economy as a result of factors such as: (i) application of traditional processes, (ii) use lower quality products, (iii) greater amount of waste produced, and (iv) higher costs, including recycling costs (Opara, 1993). Homebuilders, over the past years, have faced great difficulties. For the past few years, they have been in a place that did not require a vigorous pursuit of low prices as they enjoyed record closures with happy buyers. However, as the market slowdown and inventories rise, builders now find themselves in a situation that they have to reduce costs to have a place in this new competitive market (Build it Green, 2005).

The results of a survey of construction companies show that $65 \%$ of respondents indicate that the cost of disposing of construction waste has a negative impact on the economic health of their companies (Austin, 1991). Finding a way to reduce such amount of produced waste could help construction firms to have cost benefits in the areas of reducing waste, removing waste, and tipping costs and consequently increase the competitiveness of the builders.

\section{Definitions of Construction waste}

Construction waste has been defined in many ways. Building Research Establishment-BRE (1978) described waste as "the difference between ordered items and those reserved for repair projects". Consistent with the philosophy of the new product, waste must be understood as something inability to use equipment, materials, labour or capital as a result of inefficiency size beyond what is deemed necessary in building production. Waste includes both the incidence of fabric losses and therefore the execution of unnecessary work, which generates additional costs but do not add value to the product.

Koskela (1992) The LC concepts were based on the concepts developed for the auto industry and adapted to the environment of the Civil Construction. This term is an adaptation of the Toyota Production System (TPS) principles to construction and was described initially by Koskela (1992) that perceived alteration occurred on that industry due the use of this system and considered its application in construction. According to Koskela (1992), to implement the concepts of the Lean Thinking in the Civil Construction is necessary, initially, understand the existing concepts, and then implement them in the new environment. Koskela (1992) also presents eleven principles for flow process design and improvement

Howell (1999) LC projects are very different compared to traditional construction projects management Lean approach is to increase the performance for the client in the project, set well-defined objective obviously for the delivery process, design the product simultaneously with the process and apply production control throughout the life of the project. 
Ballard (2000) waste minimization construction project must have good planning and control. Different people accomplish these two tasks in different phases of the project. The macro or the long term planning focuses on the global objectives and the restrictions that each project has. Another important one is the short term planning, which define what tasks will be done on the next day of work.

Freitas (1995) construction waste can be defined as all over-utilized resources, in addition to the requirements for performing the work

Andrade (1999)According to the consumed resource, the waste can be classified in physical and financial waste This classification considers the following Physical waste of materials, Physical waste of man-hour, Physical material waste, Financial waste due to physical pollution, waste, related to financial waste and overuse of material, and (ii) direct waste, related to material waste, especially rubbish.

Paliari (1999)Considering the possibility of controlling or reducing the index of waste detected, the waste is classified in two categories: (i) avoidable or (ii) unavoidable. The unavoidable waste is the one that the necessary investment for its reduction is superior to the economy obtained. Generally, this waste category represents an acceptable level of waste that its factors get out of control of the builder as each company grows. On the other hand, is the one that its reduction is economically viable because the cost of waste is significantly higher than the cost to prevent it.

\section{Harris and McCaffer (2001)}

The construction waste is directly related with construction management, the lack of it can result in an increase of that waste and decrease of productivity. Construction companies pay more attention and spend more time on labor and plant control than they do on materials management. However, there are evidences that losses due materials are often higher than those due to other causes. Consequently better attention to materials control may have significant influence in the pursuit of increase profit.

Bossink et al. (1996) learned that a large portion of the waste was generated from Dutch construction projects. About $10 \%$ of used virgin materials are used to eliminate waste.The following are the main sources of waste production, Procurement, Fabric Handling, Operation and Remnants. The following are the major items of Waste stone Tablets, Tiles, Concrete, Sand bricks and materials, Roof Tiles, Mortar and Packing.

Formoso et al. (2002) learned that waste Material is a major problem for the construction industry in the agricultural industry and the environmental impact of construction projects. The study was conducted in Brazil at 74 construction sites located in various regions of the country. The research study was conducted in two separate periods from 1992-1993 and 1996-1998. The results indicate that materials waste is fairly high and that significant differences in pollution incidence are found in various projects. Most of these pollutants can be avoided by using less expensive preventive measures, which are closely linked to management development. The study argues that financial and non-monetary waste should be considered, wide-scale waste monitoring should not be considered not only in physical waste, site management is inadequate, but in addition to individual site management and individual production should be strictly regulated, waste management should be fully integrated into the planning and production process.

Nagapan et al. (2012) learned that Rapid growth in construction activities has exacerbated global construction waste problems. It contributes negatively to the environment, cost, time, productivity and nation. To minimize these negative effects, it requires a complete understanding of the generation of waste disposal for construction and management. The causes of construction pollution are matrix and it was found that there are 63 pollutants present in the construction works. The causes of pollution are organized into seven categories: Design, Handling, Worker, Management, Site Status, Purchasing and External. The frequency of the cause of the creation of each category was determined based on limitations in previous research activities that were considered and the reason for each generation of waste was determined in the studies. The following causes have been found in various courses, changes to standard designs, incorrect maintenance, personnel errors.

Bagdi et al. (2013) have learned that the Indian construction industry is developing at a rapid rate, and leads to a large amount of waste. They use secondary data based on results from a structured interview that illuminates some of the major issues, challenges and drivers associated with the implementation of waste management practices in the construction sector in India. An important result was that the introduction of customer and regulatory support actually facilitated the implementation of waste minimization and the lack of vigilance and education among construction workers were considered major challenges related to the implementation of waste reduction measures in India. Other drivers who are unable to perform the waste minimization process at the facilities for the proper training or service personnel, evacuation of the customer, and enforcement of various laws by the government and regulatory agencies. The development of building waste management legislation without an effective resource makes the perception of construction waste a misery in India.

Shetty (2013) has learned that India has established itself as one of the fastest growing economies in the world and this growth has brought significant impetus to construction activities. The faster the amount of waste is, the more it has grown. So it is necessary to manage it construction waste construction. Reduce, Reuse and Recycle is suggested for construction waste. It is estimated that the total solid waste generated in India is 960 million tons while the construction waste alone is 14.5 million tons. The construction and demolition waste in India in 2010 is estimated at 24 million tonnes. Author suggests that waste should prevent at the time construction activity, maximum effort should made to recycling of material and reusing the material.

Thomas et al. (2013) learn that, the lack of availability of concrete manufacturing mixes is an important problem facing the construction industry. The construction industry accounts nearly 11 percentages of India's gross domestic product. It has been 
seen that the total cost of material is nearly 40 to 60 percentage of total project cost. Therefore, India has the potential to be cost effective to be millions of Rupees by adopting suitable measures for waste management. The total quantum of C\&D waste generated in India is estimated at 11.4 to 14.69 million tonnes. So he suggests enlightens the importance of reduce, reuse and recycle (3R) concept for managing the construction waste in India

\section{METHODOLOGY}

In this study, questionnaires will be used as a tool for collecting data for quantitative analysis. The questionnaire is the most common method used to acquire the opinions of the respondents in a structured manner. Although designing a questionnaire appears to be relatively simple, it is a complex process. The questions must be formulated and selected carefully and the aim of the research must continuously be borne in mind. Due to the nature of the research, of course it is important to ensure respondents of confidentiality with which answer would be treated as it could drastically influence the accuracy of results. Therefore, this feature was greatly appreciated during the instruction phase.

Severity index (SI) is a computation that is used to rank the types of waste for each category according to their degree of influence in affecting final project cost. In order to evaluate the degree of influence of each type of waste a three-point scale was used as follows:

$1=$ (highly significant)

$2=($ moderately significant $)$

$3=($ not significant $)$

Severity index $=\sum_{i=1}^{3}(W i * f i) * \frac{1}{n}$

Where i represents the ratings 1-3, fi the frequency of responses, $n$ the total number of responses and Wi the weight for each rating. The types of waste with higher SI have more influence in affecting final residential construction project. The third and last step of the data analysis is to determine the possible causes of the occurrence of the type of waste for top three waste categories. The weighting factor are given as per the degree of influence of the type of waste on cost

\begin{tabular}{|l|c|}
\hline \multicolumn{1}{|c|}{ ACTIVITY } & RANK \\
\hline Excavation & 13 \\
\hline Foundation work & 10 \\
\hline Plinth filling & 13 \\
\hline Column casting & 20 \\
\hline RCC Work (Beam and column casting) & 28 \\
\hline Brickwork & 25 \\
\hline plastering & 13 \\
\hline Painting work & 11 \\
\hline Tiling work & 9 \\
\hline Electrical work & 10 \\
\hline Plumbing work & 11 \\
\hline Water proofing & 9 \\
\hline Drainage work & 9 \\
\hline Door and Window fitting & 9 \\
\hline
\end{tabular}

Table 1: Maximum rank table for First questionnaire

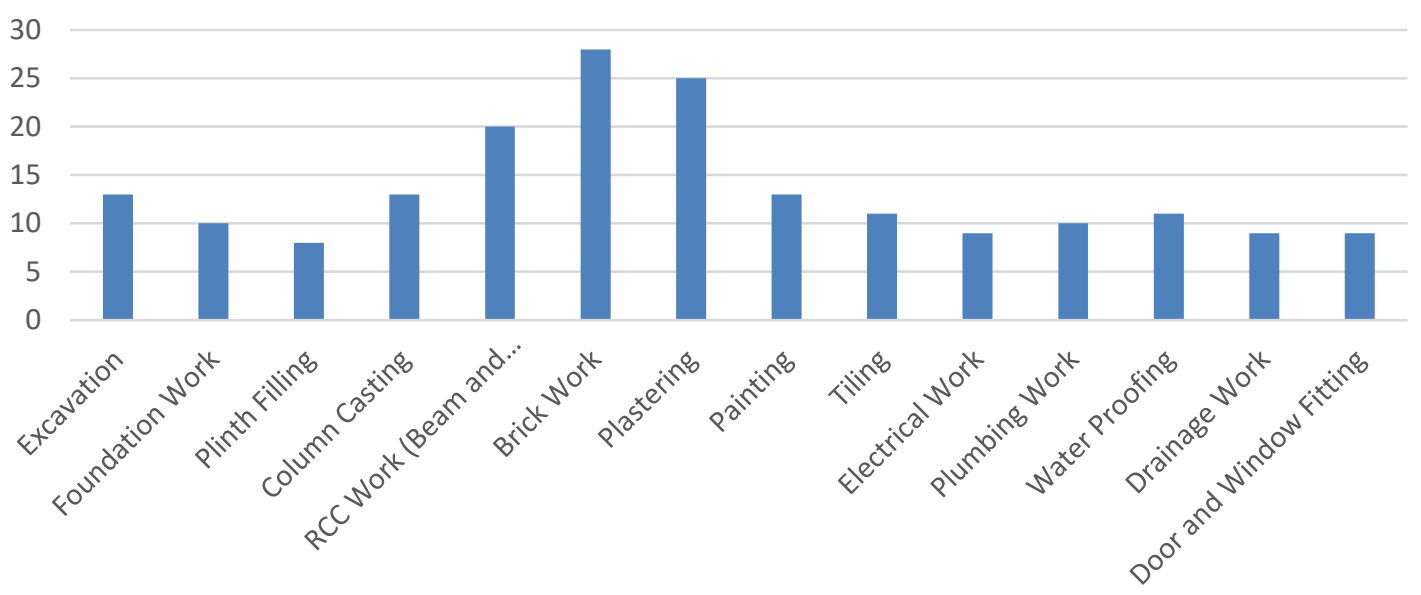

Figure 1: Result of first questionnaire 


\begin{tabular}{|c|c|c|c|}
\hline No & Type of waste & Rank & Causes \\
\hline 1 & Delay & & \\
\hline 2 & waste of materials & & \\
\hline 3 & deterioration of materials & & \\
\hline 4 & inefficient movement of workers & & \\
\hline 5 & material purchased with superior value & & \\
\hline 6 & waiting or idle & & \\
\hline 7 & unnecessary work & & \\
\hline 8 & rework & & \\
\hline 9 & over allocation of materials & & \\
\hline 10 & waste of space on site, & & \\
\hline 11 & unnecessary handling of materials & & \\
\hline 12 & Accidents & & \\
\hline
\end{tabular}

Table 2: Second questionnaire

\begin{tabular}{|c|c|c|}
\hline \multirow[t]{2}{*}{ a) } & \multicolumn{2}{|c|}{ Design } \\
\hline & a.1 & Lack of knowledge in availability of alternate materials \\
\hline & a. 2 & Insufficient drawing details \\
\hline & a.3 & Complex design difficult to execute \\
\hline & a. 4 & Ambiguity in specifications \\
\hline & a.5 & Improper co-ordination \\
\hline & a.6 & Rework due to change in design \\
\hline & a.7 & Improper planning \\
\hline \multirow[t]{3}{*}{ b) } & \multicolumn{2}{|c|}{ Procurement } \\
\hline & b.1 & Materials not received on time \\
\hline & b.2 & Improper quality of material \\
\hline \multirow[t]{3}{*}{ c) } & \multicolumn{2}{|c|}{ Material handling } \\
\hline & c. 1 & Improper storage \\
\hline & c. 2 & Improper handling ( on site or off site) \\
\hline \multirow[t]{4}{*}{ d) } & \multicolumn{2}{|c|}{ Construction and rework } \\
\hline & d.1 & Poor workmanship \\
\hline & d.2 & Lack of site waste management plan \\
\hline & d.3 & Equipment malfunctioning causing rework \\
\hline \multirow[t]{3}{*}{ e) } & \multicolumn{2}{|c|}{ Project Management } \\
\hline & e.1 & Lack of project planning and management techniques \\
\hline & e. 2 & Lack of control techniques \\
\hline \multirow[t]{6}{*}{ f) } & \multicolumn{2}{|c|}{ Execution } \\
\hline & f.1 & Poor teamwork \\
\hline & f.2 & Execution methods adopted \\
\hline & f. 3 & Poor Arrangement of the working place \\
\hline & f. 4 & Lack of personal equipment \\
\hline & f.5 & Lack of safety management plan \\
\hline \multirow[t]{5}{*}{ g) } & \multicolumn{2}{|c|}{ Human Resources } \\
\hline & g.1 & Lack of skill \\
\hline & g.2 & Inadequate training facilities \\
\hline & g.3 & Improper utilization of human resources \\
\hline & g.4 & Excess work allocation \\
\hline \multirow[t]{4}{*}{ h) } & \multicolumn{2}{|c|}{ Information Systems } \\
\hline & h.1 & Lack of information \\
\hline & h.2 & Information not updated \\
\hline & h.3 & Lack of MIS \\
\hline
\end{tabular}

Table 3: List of Causes for Waste Generation 


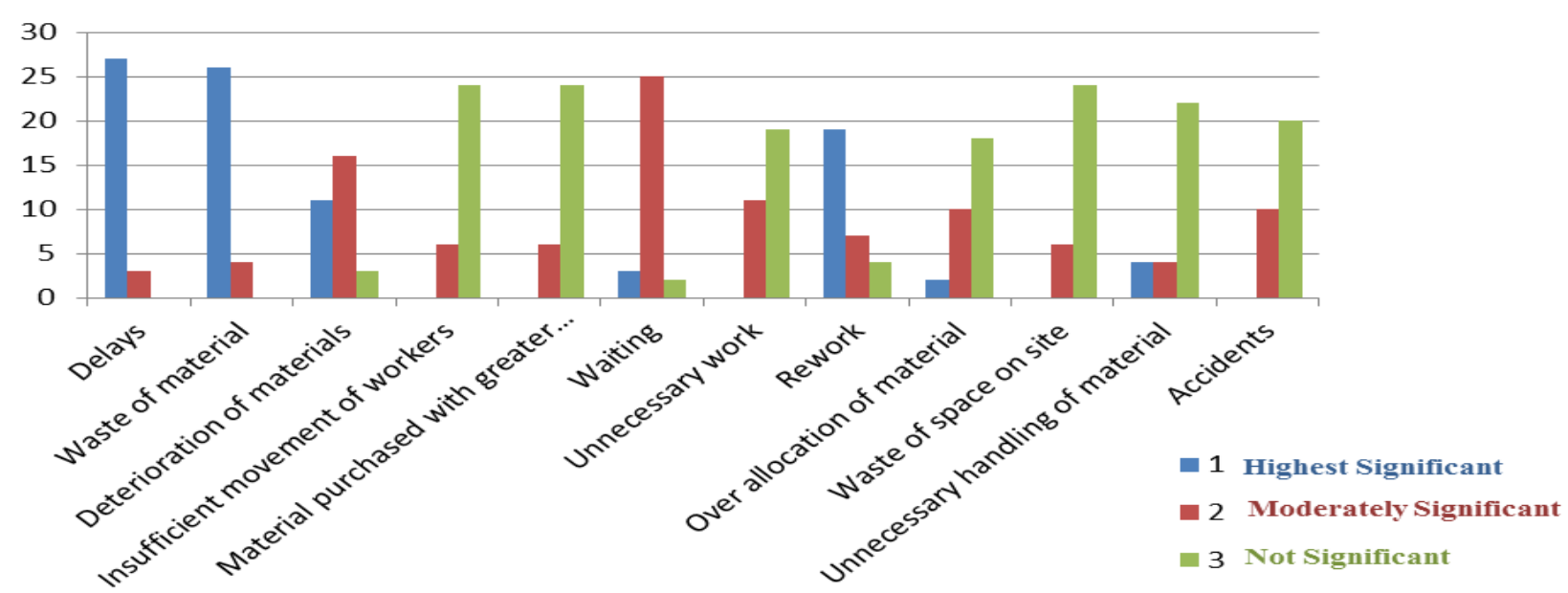

Figure 2: Result of second questionnaire

\section{DATA ANALYSIS USING R}

$\mathrm{R}$ is a programming language introduced by Ross Ihaka and Robert Gentleman in 1993. R has a comprehensive catalog of mathematical and graphical methods. R offers a variety of mathematical models (linear and offline programming, classical mathematical analysis, time series processing, segmentation, compilation,) and graphing techniques, and is greatly expanded From the data obtained from questionnaire 1 and questionnaire 2 i.e. frequency and level of significance of activities on the generation of wastages as above, the Severity index is calculated in order to find the parameter that accrues the wastage in Construction activity.

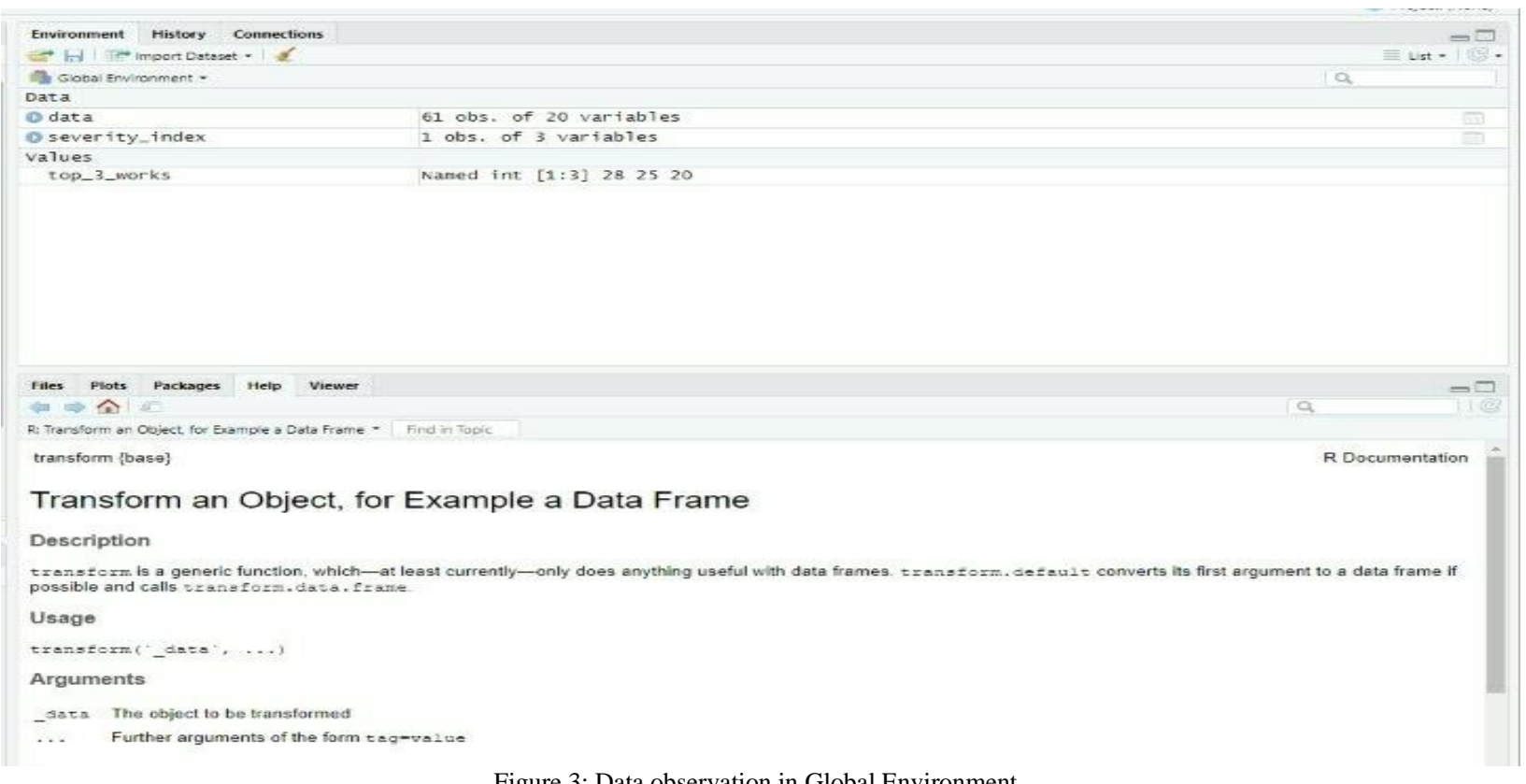

Figure 3: Data observation in Global Environment 


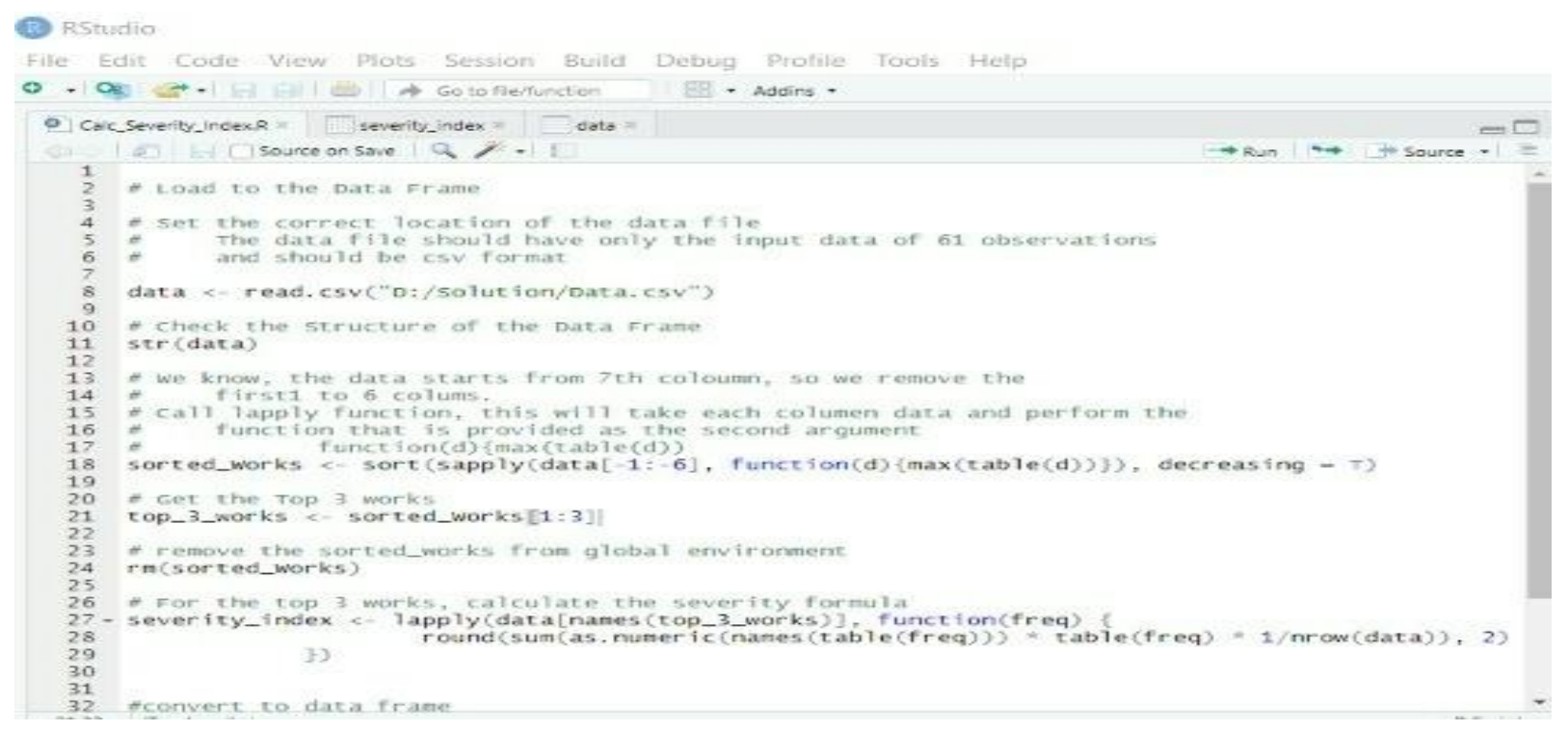

Figure 4: Input for Data execution in R studio

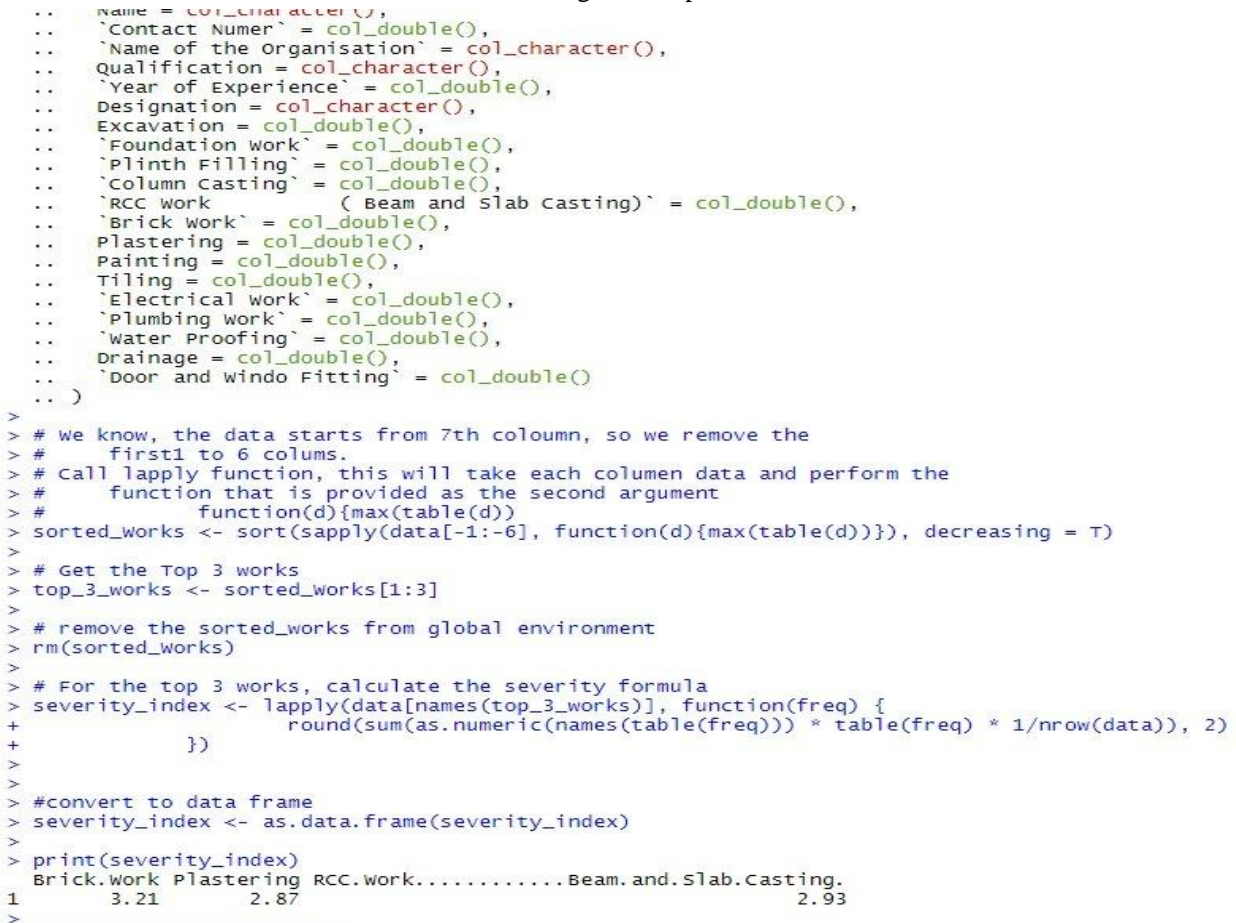

Figure 5: Analysis of top three activities in console

\begin{tabular}{|l|l|}
\hline Severity Index for the Types of Waste on Reinforced Cement Concrete, Brickwork, and Plastering \\
\hline Delay & 2.90 \\
\hline waste of materials & 2.87 \\
\hline deterioration of materials & 2.27 \\
\hline inefficient movement of workers & 1.20 \\
\hline material purchased with superior value & 1.20 \\
\hline waiting or idle & 2.03 \\
\hline unnecessary work & 1.37 \\
\hline rework & 2.50 \\
\hline over allocation of materials & 1.47 \\
\hline waste of space on site, & 1.20 \\
\hline unnecessary handling of materials & 1.40 \\
\hline Accidents & 1.33 \\
\hline
\end{tabular}

Table 4: Severity Index calculation 


\section{CONCLUSION}

It can be concluded from research that a systematic consideration of waste management is helpful identify the major causes of contamination. Once identified, it can be avoided or reduced resulting in greater capital gains for the firm. Residential constructions were selected for the study. It is observed from analysis of data that Reinforced cement concrete, Plastering, Brickwork are the major wastes causing Based upon the various literatures reviews. Various factors causing construction waste can be identified. And with the appropriate method of data analysis the most significant factors influencing the construction waste can be analysed using $\mathrm{R}$ programming. Based on the reviews it was identified that Delay, Waste of Material, Deterioration of materials, Rework, Waiting can yield to construction waste. Based on this analysis recommendations were given to firms Future studies can be done on different types of projects such as infrastructure projects, water supply, industrial and other specialties.

\section{REFERENCES}

[1] Clough, R. H., Sears, G. A. and Sears, S. K. (2000) Construction project management ( $4^{\text {th }}$ ed.) John Wiley \& Sons, Inc. New York

[2] Opara, E. O. (1993) A Quantitative Model to Predict the Cost of Quality Nonconformance in the Construction Industry. M.S. Thesis. Texas A\&M University, College Station.

[3] Build it Green (2005) New Home Construction Green Building, available at http:// www. builditgreen.org/newconstructionguidelines.pdf Austin, T. (1991). Building green. Civil Engineering, August, 52-54.

[4] Austin, T. (1991). Building green. Civil Engineering, August, 52-54.

[5] Koskela, L. (1992) Application of the New Production Philosophy to Construction. Technical Report \#72, CIFE, Stanford University, Stanford, CA.

[6] Howell, G. (1999), What is lean construction. In: Proceedings of the Conference of International Group of Lean Construction 7, 1-10. Berkeley, CA

[7] Ballard, H.G. (2000). The Last Planner System of Production Control. Ph.D. Dissertation, School of Civil Engineering, University of Birmingham, U.K.

[8] Cristiano R. Castelo Branco(2007) "An Effective Way to Reduce Residential Construction Waste : A Case Study In Texas, December"

[9] Rao B.P., Shivakumar B., Suresh H. S. "Waste Minimization in Construction Industry", Indian Journal of Applied Research, Volume-4, Issue-6, ISSN 2249-555x, 2014.

[10] 10.Ashish H.Makwana.,"sourceidentification and minimization of waste in building construction using rii and imp.i. method" ISBN: 978-81-929339-3-1

[11] Usman Aminu Umar.,|" Ranking of Principal Causes of Construction Waste for MalaysianResidential Project".

[12] Bossink B.A.G., Brouwers H.J.H., "Construction Waste: Quantification and Source Evaluation”, Journal of Construction Engineering and Management, ISSN: 0733-9364, 1996.

[13] FORMOSO, C. T., SOIBELMAN, L., DE CESARE, C. \& ISATTO, E. L. 2002. Material waste in building industry: main causes and prevention Journal of construction engineering and management, 128, 316-325.

[14] NAGAPAN, S., RAHMAN, I. A. \& ASMI, A. 2012. Factors Contributing to Physical and Non-Physical Waste Generation in Construction Industry. International Journal of Advances in Applied Sciences, 1, 1-10.

[15] Bagdi N., Aggarwal V., Sherwal N., "Management of Construction Waste in India: A Case of Green Technology", Global Journal of Management and Business Studies. ISSN: 2248-9878, Volume-3, Number4, 2013.

[16] Shetty R. S. "Construction and Demolition Waste-An Overview of Construction Industry in India", International Journal of Chemical, Environmental \& Biological Sciences (IJCEBS), Volume 1, Issue 4, EISSN: 2320-4087, 2013.

[17] 17.Thomas J., Wilson P. M., "Construction Waste Management in India", American Journal of Engineering Research, E-ISSN: 2320-0847, P-ISSN: 23200936, Volume-2, Pg-06-09, 2013 